\title{
A decrease in anaerobic bacteria promotes Candida glabrata overgrowth while $\beta$-glucan treatment restores the gut microbiota and attenuates colitis
}

\author{
Rogatien Charlet ${ }^{1,2,3}$, Clovis Bortolus ${ }^{1,2,3}$, Melissandre Barbet ${ }^{1,2,3}$, Boualem Sendid ${ }^{1,2,3}$ and Samir Jawhara ${ }^{1,2,3^{*}}$ (1)
}

\begin{abstract}
Background: The intestinal microbiota plays a crucial role in the maintenance of gut homeostasis. Changes in crosstalk between the intestinal epithelial cells, immune cells and the microbiota are critically involved in the development of inflammatory bowel disease. In the experimental mouse model, the development of colitis induced by dextran sulfate sodium (DSS) promotes overgrowth of the opportunistic yeast pathogen Candida glabrata. Conversely, fungal colonization aggravates inflammatory parameters. In the present study, we explored the effect of C. glabrata colonization on the diversity of the gut microbiota in a DSS-induced colitis model, and determined the impact of soluble $\beta$-glucans on C. glabrata-host interactions.

Results: Mice were administered a single inoculum of C. glabrata and were exposed to DSS treatment for 2 weeks in order to induce acute colitis. For $\beta$-glucan treatment, mice were administered with soluble $\beta$-glucans purified from C. glabrata (3 mg per mouse), orally and daily, for 5 days, starting on day 1. The number of C. glabrata colonies and changes in microbiota diversity were assessed in freshly collected stool samples from each tagged mouse, using traditional culture methods based on agar plates. An increase in Escherichia coli and Enterococcus faecalis populations and a reduction in Lactobacillus johnsonii and Bacteroides thetaiotaomicron were observed during colitis development. This decrease in L. johnsonii was significantly accentuated by C. glabrata overgrowth. Oral administration of $\beta$-glucans to mice decreased the overgrowth of aerobic bacteria and IL-1 $\beta$ expression while L. johnsonii and B. thetaiotaomicron populations increased significantly. $\beta$-glucan treatment increased IL-10 production via PPARY sensing, promoting the attenuation of colitis and C. glabrata elimination.
\end{abstract}

Conclusions: This study shows that the colonic inflammation alters the microbial balance, while $\beta$-glucan treatment increases the anaerobic bacteria and promotes colitis attenuation and C. glabrata elimination.

Keywords: $\beta$-Glucans, Candida glabrata, Microbiota, Colitis, Anaerobic bacteria, Escherichia coli, Enterococcus faecalis

\section{Background}

The commensal intestinal microbiota helps to maintain stability and prevent overgrowth or infection with pathogenic bacteria. Gut microbiota dysbiosis has been

\footnotetext{
*Correspondence: samir.jawhara@univ-lille.fr

${ }^{2}$ LIRIC-INSERM U995/2, Lille Inflammation Research International Center, University Lille, 1 Place Verdun, 59000 Lille, France

Full list of author information is available at the end of the article
}

associated with inflammatory bowel diseases (IBDs) [1]. IBDs are chronic inflammatory diseases of the gastro-intestinal (GI) tract, and include Crohn's disease (CD) and ulcerative colitis (UC) [2]. Disruption of the gut microbiota as well as impairment of host immunity give rise to perturbations promoting the overgrowth of opportunistic yeast species such as Candida albicans, leading to increased yeast translocation and susceptibility to systemic infection [3-5]. Like $C$. albicans, $C$. glabrata can cause infections ranging from mucosal 
lesions to bloodstream or invasive infections in patients with altered immune or physiological responses [6]. The cell wall of C. glabrata plays a crucial role in the interaction of the yeast with its host. The yeast cell wall mainly contains of carbohydrate polymers linked with glycoproteins and phospholipids [7]. The three major components are $\beta$-glucans (polymers of glucose), chitin (a polymer of $N$-acetylglucosamine), and mannans [7]. $\beta$-1,3-glucans provide the major structural scaffold of the yeast cell wall and have different amounts of $\beta-1,6$ branches.

Different studies have demonstrated the biological properties of $\beta$-glucans, particularly their anti-inflammatory, antioxidant, and anti-tumor effects [8-10]. $\beta$-glucans can directly activate leukocytes, and further stimulate their phagocytic, cytotoxic, and antimicrobial activities. $\beta$-glucans are recognized by several receptors, in particular integrin $\alpha_{M} \beta_{2}$, dectin-1 and TLR-4, thereby triggering an immune response [11-13].

In the present study, we studied the effect of $\beta$-glucans on the biodiversity of the gastrointestinal tract microbiota in a dextran sulfate sodium (DSS)-induced colitis model. We also analyzed the effect of $\beta$-glucans on intestinal inflammation and elimination of C. glabrata from the gut.

\section{Results}

The impact of C. glabrata colonization on intestinal inflammation and gut microbiota changes was determined in a DSS induced-colitis model. The effect of oral administration of $\beta$-glucan on intestinal inflammation, the gut microbiota, and C. glabrata elimination was also investigated.

\section{Determination of inflammatory parameters}

Mice were exposed to 2\% DSS in drinking water for 2 weeks to induce colitis. Mice developed colitis with inflammatory clinical signs of diarrhea, gross rectal bleeding, and body weight loss, starting from day 6 after DSS treatment (Fig. 1). Mice given water (control), C. glabrata only, or $\beta$-glucans showed no clinical signs of inflammation. In contrast, mice given DSS or $C$. glabrata-DSS showed body weight loss and an increase in the clinical score for inflammation. $\beta$-glucan treatment significantly reduced the clinical score for inflammation in C. glabrata-DSS mice (Fig. 1b).

The histologic score was significantly higher in $C$. glabrata-DSS mice than in DSS-treated mice (Fig. 1c). In contrast, $\beta$-glucan treatment significantly reduced the clinical and histologic scores of inflammation in C. glabrataDSS mice. High leukocyte infiltrates, cryptic abscesses, and loss of epithelium occurring throughout the colon mucosa and submucosa were more frequently observed in the colons of C. glabrata-DSS mice than in mice treated with DSS. $\beta$-glucan administration reduced leukocyte infiltrates, epithelial damage and mucosal abscesses (Fig.1d).

\section{C. glabrata colonization and modification of the gut microbiota during colitis development}

The number of C. glabrata CFU was determined on day 14 in stool samples collected from each tagged mouse (Fig. 2). C. glabrata colonies increased significantly during the development of colitis when compared to mice given C. glabrata only or mice treated with $\beta$-glucans. To assess the changes in microbiota diversity during colitis development, stool samples were collected daily from each tagged mouse, and bacteria were isolated using traditional culture methods based on agar plates. The number of E. coli and E. faecalis colonies increased from day 10 to day 14 in both DSS and C. glabrataDSS groups when compared to controls, C. glabrata or $\beta$-glucan groups, suggesting that regardless of $C$. glabrata colonization, colitis development promotes an increase in E. coli and E. faecalis populations in mice (Fig. 3).

In terms of anaerobic bacteria, the number of $B$. thetaiotaomicron decreased significantly, starting from day 10 to day 14 in both DSS and C. glabrata-DSS mice, while treatment of mice with $\beta$-glucans increased the number of $B$. thetaiotaomicron. The number of $L$. johnsonii colonies was reduced significantly starting from day 2 to day 14 in both DSS and C. glabrata-DSS mice, but the reduction in the $L$. johnsonii population was significantly more pronounced in the C. glabrata-DSS group, suggesting that C. glabrata overgrowth has an impact on the L. johnsonii population during the development of colitis (Fig. 3). In contrast, treatment of mice with $\beta$-glucans significantly increased the number of $L$. johnsonii in C. glabrata-DSS mice (Fig. 4).

\section{Analysis of cytokine and receptor expression}

Expression of IL-1 $\beta$ was significantly higher in the colons of C. glabrata-DSS mice than in DSS treated mice, whereas the expression of this cytokine was significantly lower in the colons of mice treated with $\beta$-glucans (Fig. 5). Additionally, expression of IL-10 was significantly lower in the colons of C. glabrata-DSS or DSS alone groups. Conversely, treatment of mice with $\beta$-glucans significantly increased the expression of IL-10 in C. glabrata-DSS mice. In terms of PPAR $\gamma$ expression, $\beta$-glucan treatment significantly increased the expression of this receptor in the colons of C. glabrata-DSS groups (Fig. 5).

\section{Discussion}

IBDs are a group of chronic multifactorial disorders. Although the etiology of IBDs remains unknown, several studies have reported that the immune system, genetic 
susceptibility, and the environmental factors have all been implicated in its pathogenesis $[1,14,15]$. Involvement of the gut microbiota in the pathophysiology of IBDs has been highlighted [16]. Several studies have shown reduced diversity of the gut microbiota in IBD patients $[4,17]$. Furthermore, patients with $C D$ are highly colonized with Candida spp., in particular, C. albicans [18]. Consistently, in a murine model, intestinal inflammation induced chemically by DSS promotes Candida spp. colonization. In turn, fungal colonization exacerbates intestinal inflammation $[3,19]$. The present study focused on the most representative cultivable anaerobic and aerobic bacteria that can undergo changes during intestinal inflammation $[1,20]$. We focused in particular on cultivable bacteria belonging to the phyla Firmicutes, Bacteroidetes, Proteobacteria or Actinobacteria by using selective bacterial media since these bacteria are known for their possible involvement in Crohn's disease, i.e. $E$. coli and E. faecalis [21].

An increase in E. coli and E. faecalis populations in mice that developed colitis was observed. These data are consistent with clinical and experimental studies, which show an increase in E. coli and E. faecalis in CD patients $[4,20]$. In addition to an increase in the population of opportunistic E. coli, the development of colitis is characterized by high levels of reactive oxygen species (ROS) and nitrogen species, and these are considered hazardous to bacteria. However, the $E$. coli population is armed with multiple strategies to help their survival from ROS [22]. Additionally, tissue damage during colitis could serve as potential nutrients, such as ethanolamine, to encourage E. coli overgrowth $[23,24]$.

In terms of anaerobic bacteria, B. thetaiotaomicron and $L$. johnsonii decreased in response to intestinal inflammation, while C. glabrata colonization increased during the development of colitis. Interestingly, the reduction in the $L$. johnsonii population was more pronounced in the C. glabrata-DSS group, suggesting that Lactobacillus growth can antagonize colonization by Candida spp. [25].

The first point of contact between C. glabrata and its host is the fungal cell wall, whose major constituent is $\beta$-glucan. The biological activity of $\beta$-glucans is related to their molecular structure, including their solubility, their degree of branching, and their effect on the inhibition or activation of host pattern recognition receptors [13]. This study used soluble short fractions of $\beta$-glucans, purified from $C$. glabrata in a DSS-induced colitis model. Orally administered $\beta$-glucans decreased intestinal inflammation and C. glabrata overgrowth. This observation is consistent with our previous study, which showed that oral administration of soluble $\beta$-glucans derived from $C$. albicans reduced leukocyte infiltration into the gut mucosa and enhanced mouse survival in the DSS model [9]. Additionally, oral administration of $\beta$-glucans increased $B$. thetaiotaomicron and $L$. johnsonii populations in C. glabrata-DSS groups. The combination of oat $\beta$-glucans and Lactobacillus spp. has consistently been shown to increase the viability of these microorganisms within food matrices [26].

The anti-inflammatory activities of $\beta$-glucans from fungi have been emphasized in different studies, which have shown that soluble $\beta$-glucans can activate or block different receptors such as CD11b/CD18, dectin-1, or TLR-4 [11, 27]. Recently, short fractions of $\beta$-glucans were shown to block the activation of platelets mediated by TLR- 4 expression [13]. $\beta$-glucans can initiate the innate immune response and then trigger effective immune responses including phagocytosis and cytokine production that lead to fungal elimination. It has been shown that soluble $\beta$-glucans were captured via macrophages and dendritic cells (DCs) present in Peyer's patches and induced DC maturation via the dectin-1 pathway [28]. In line with this observation, $\alpha$-glucan induced the maturation of DCs and was dependent on TLR2 and promoted anti-inflammatory regulatory $\mathrm{T}$ cell responses [29].

In the present study, C. glabrata overgrowth reduced IL-10 expression during the development of colitis, while $\beta$-glucan treatment increased IL-10 production via PPAR $\gamma$ sensing. These data are consistent with the previous study, which indicates that $\beta$-glucan treatment reduces pro-inflammatory cytokine expression [9]. Mice deficient in IL-10 showed an increase in IL-1 $\beta$ levels that promoted uncontrolled inflammation in the intestine [30]. Additionally, inhibition of IL-1 $\beta$ activity with a receptor antagonist has been shown to decrease intestinal inflammation in a murine model of colitis [31].

\section{Conclusions}

The development of colitis promotes an increase in the aerobic bacteria population, in particular E. coli and $E$. faecalis, but a reduction in the anaerobic bacteria population, such as L. johnsonii, and B. thetaiotaomicron. In terms of fungal cell wall components, oral administration of $\beta$-glucans to mice decreased the overgrowth of aerobic bacteria and C. glabrata as well as the production of inflammatory parameters. $\beta$-glucan treatment increased IL-10 production via PPAR $\gamma$ sensing, promoting the attenuation of colitis and C. glabrata elimination. We are currently analyzing the metabolites released by anaerobic bacteria during the development of colitis to determine the molecules involved in the anti-inflammatory process. In a similar way, our previous work showed an interaction between Candida spp., E. coli, and Serratia marcescens to 
form robust biofilms where lipopolysaccharide produced by $S$. marcescens and $E$. coli significantly increased fungal biofilm maturation [4].

\section{Methods}

\section{C. glabrata strain and culture conditions}

Candida glabrata wild-type strain (ATCC, $\mathrm{Cg}$ ) is used. The yeast is grown in liquid YPD medium (yeast extract
$1 \%$, peptone $1 \%$, dextrose $1 \%$ ), on a rotary shaker for $18 \mathrm{~h}$ at $37^{\circ} \mathrm{C}$. The culture obtained is then centrifuged at $2500 \mathrm{rpm}$ for $5 \mathrm{~min}$ and washed twice in phosphate buffer saline (PBS).

\section{Extraction of $\beta$-glucans from $C$. glabrata}

The extraction and assay of $\beta$-glucans are carried out as described previously [9]. Briefly, C. glabrata cell pellet

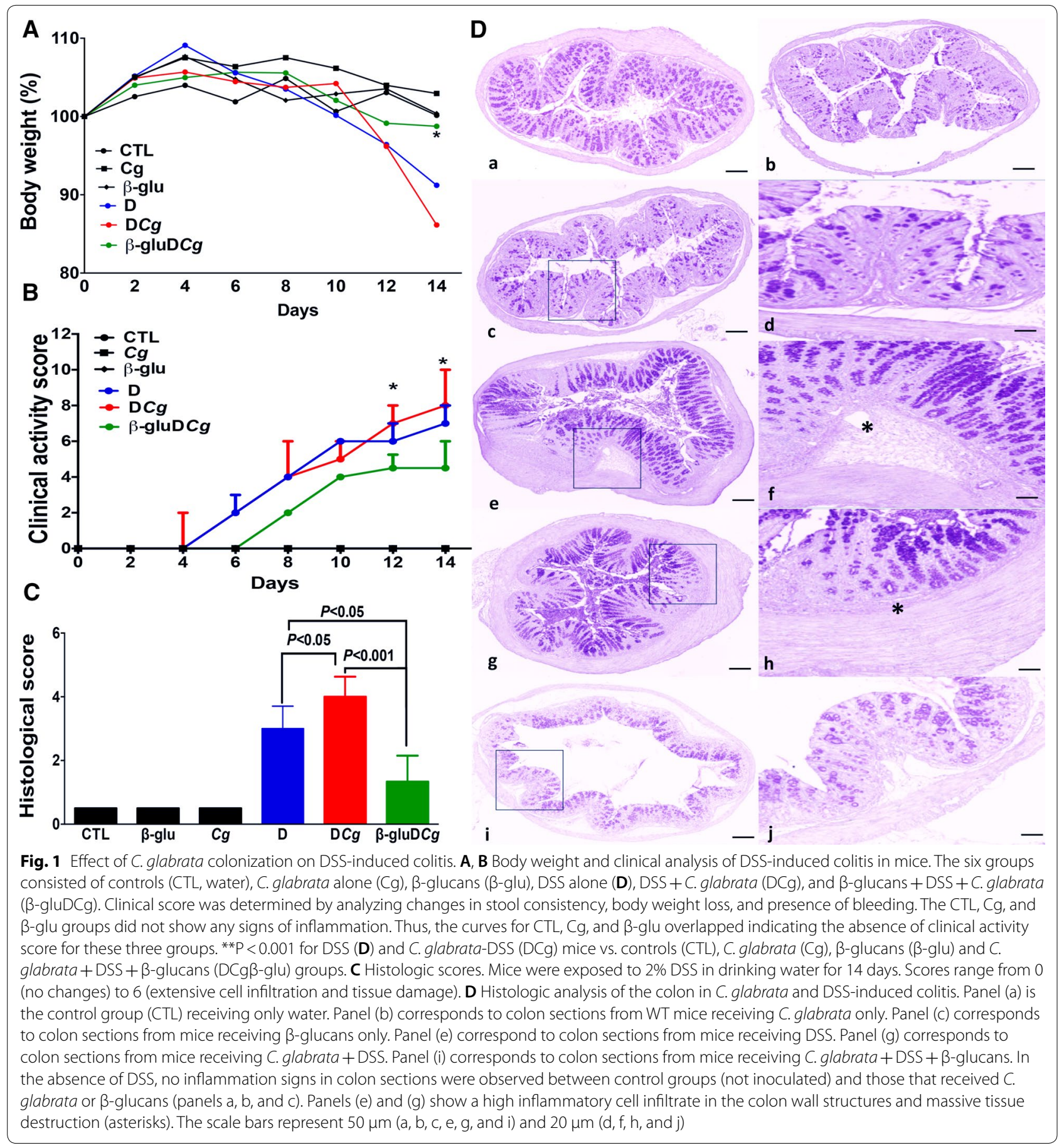


was treated twice with $200 \mathrm{~mL}$ of $1 \mathrm{M} \mathrm{NaOH}$ at $70{ }^{\circ} \mathrm{C}$ for $30 \mathrm{~min}$. The cell pellet was then washed twice with distilled water, the supernatant was discarded and the pellet was oxidized with $100 \mathrm{mM} \mathrm{NaIO}$ 4 (Sigma-Aldrich, France) at room temperature for 3 days in the dark room. After completion of the reaction, excess periodate was destroyed by adding ethylene glycol. The reduction of the pellet was performed with $1 \mathrm{M} \mathrm{NaBH} 4$ (Sigma Aldrich, France) at room temperature. The reaction was ended by decreasing the $\mathrm{pH}$ to 5 by the addition of acetic acid. After different times of washing with distilled water, the insoluble fraction was incubated with zymolyase $20 \mathrm{~T}$ $\left(0.2 \mathrm{mg} / \mathrm{mL}\right.$, Immuno ${ }^{\mathrm{TM}}$; ICN Biomedicals Inc.) at $37{ }^{\circ} \mathrm{C}$ for $3 \mathrm{~h}$. Zymolyase was inactivated at $80{ }^{\circ} \mathrm{C}$ for $10 \mathrm{~min}$. After centrifugation, the supernatant was dialyzed against distilled water. The dialyzed solution was loaded onto a Sep-Pak C18 column (Alltech) equilibrated with $0.1 \%$ trifluoroacetic acid. The evaporation of the Eluate from Sep-Pak column was performed and the resulting oligoglucosaccharides were resuspended in distilled water. Further, these oligoglucosaccharides were loaded onto a carbograph column (Alltech carbograph SPE column). Eluate from the carbograph column was the soluble $\beta$-glucan fractions. The nature and purity of the soluble $\beta$-glucan fractions are then confirmed by mass spectrometry and NMR analyses. The concentration of $\beta$-glucan fractions is measured using sulfuric acid and phenol (5\%) in 96-well plates $[9,13]$.

\section{Animals}

Ten-to-12-week-old, female C57BL/6 mice are used (Charles River Laboratories, France). Mice are allocated to one of three experimental groups or three control groups. A group of healthy mice is used as controls (CTL, 5 mice). A second group of mice receive oral gavage with C. glabrata without any other treatment ( $\mathrm{Cg}, 5$ mice). A third group are treated with $\beta$-glucan fractions ( $\beta$-glu, 5 mice). A fourth group are treated with DSS (D, 10 mice). A fifth group are treated with DSS and oral gavage with C. glabrata (DCg, 12 mice). A sixth group are given DSS and oral gavage with C. glabrata and treated with $\beta$-glucans ( $\beta$-gluDCg, 6 mice).

All animal experiments were approved by the subcommittee for Research Animal Care, Regional Hospital Center, Lille, France (00550.05), and were in accordance with institutional (86/609/CEE) and European guidelines for the care and use of laboratory animals.

\section{Inoculum preparation and induction of colitis}

The mice are given $200 \mu \mathrm{L}$ PBS containing $5 \times 10^{7}$ live $C$. glabrata cells on day 1 by oral gavage. From day 1 to day 14 , mice are also treated with $2 \%$ DSS $(36-50 \mathrm{kDa}$; MP Biomedicals, LLC, Germany) in drinking water in order

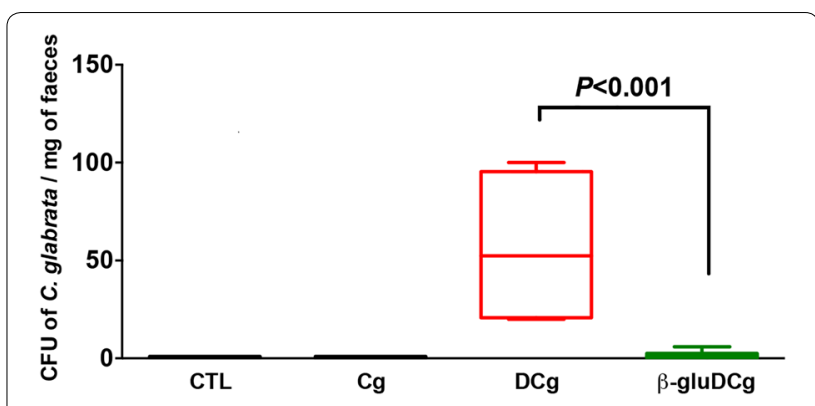

Fig. 2 C. glabrata colonization in mouse DSS-induced colitis. Number of C. glabrata colony forming units (CFU) recovered from stools

to induce colitis. For $\beta$-glucan treatment, mice are given $\beta$-glucans purified from $C$. glabrata ( $3 \mathrm{mg}$ per mouse) orally and daily for 5 days, starting on day 1 . The presence of C. glabrata in the gut is determined by measuring the number of colonies in feces (approximately $0.1 \mathrm{~g} /$ sample) collected from each animal at day 14. Fecal samples are suspended in $1 \mathrm{~mL}$ PBS, and samples are then cultured on Candi-Select medium (Bio-Rad Laboratories, France). The results are expressed as CFU/mg of feces [32].

\section{Isolation of bacteria}

Serial dilutions of fecal samples collected from the mice are performed daily. The samples are cultured on nonselective bacterial media (AC agar) focusing on the most representative cultivable anaerobic and aerobic bacteria that can undergo changes during intestinal inflammation. Isolation of aerobic bacteria and anaerobic bacteria is carried out as described previously [33]. Identification of bacteria isolated on selective media is performed by MALDI TOF mass spectrometry [33].

\section{Assessment of clinical and histologic scores}

The body weight of the mice is recorded daily. Data are expressed as mean percent change from initial body weight. Clinical scores ranging from 0 to 12 and histologic scores ranging from 0 to 6 are assessed as described previously $[19,33]$.

\section{Real-time mRNA quantification of cytokines and receptor expression}

Nucleospin RNA kit is used to extract total RNA from mouse colons (Macherey-Nagel). RNA is measured by spectrophotometry (Nanodrop; Nyxor Biotech, France). mRNA reverse transcription is performed from $1 \mu \mathrm{g}$ total RNA using a high capacity cDNA-RT kit (Applied Biosystems) in a final volume of $20 \mu \mathrm{L}$ [34, 35]. cDNA synthesis is carried out by PCR in the one-step system (Applied Biosystems) using Fast SYBR green (Applied 

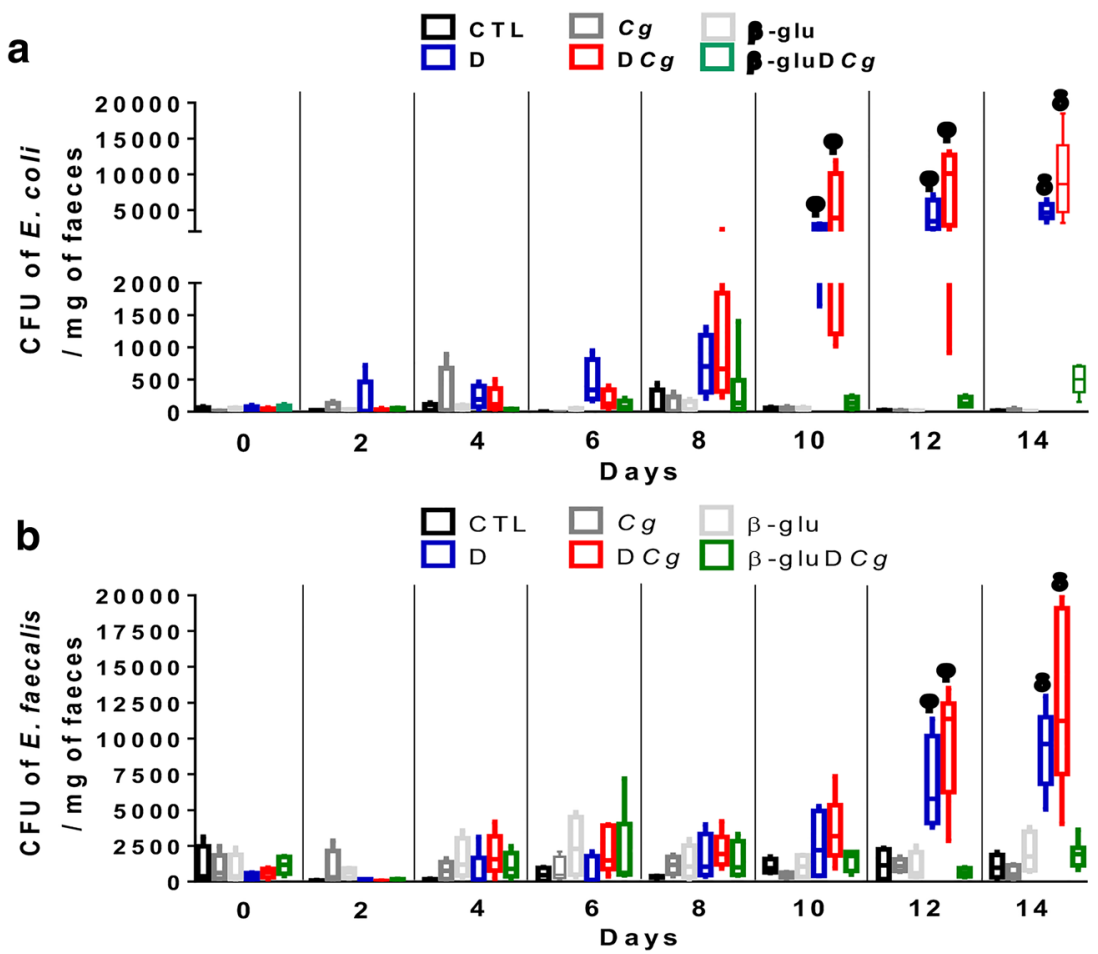

C
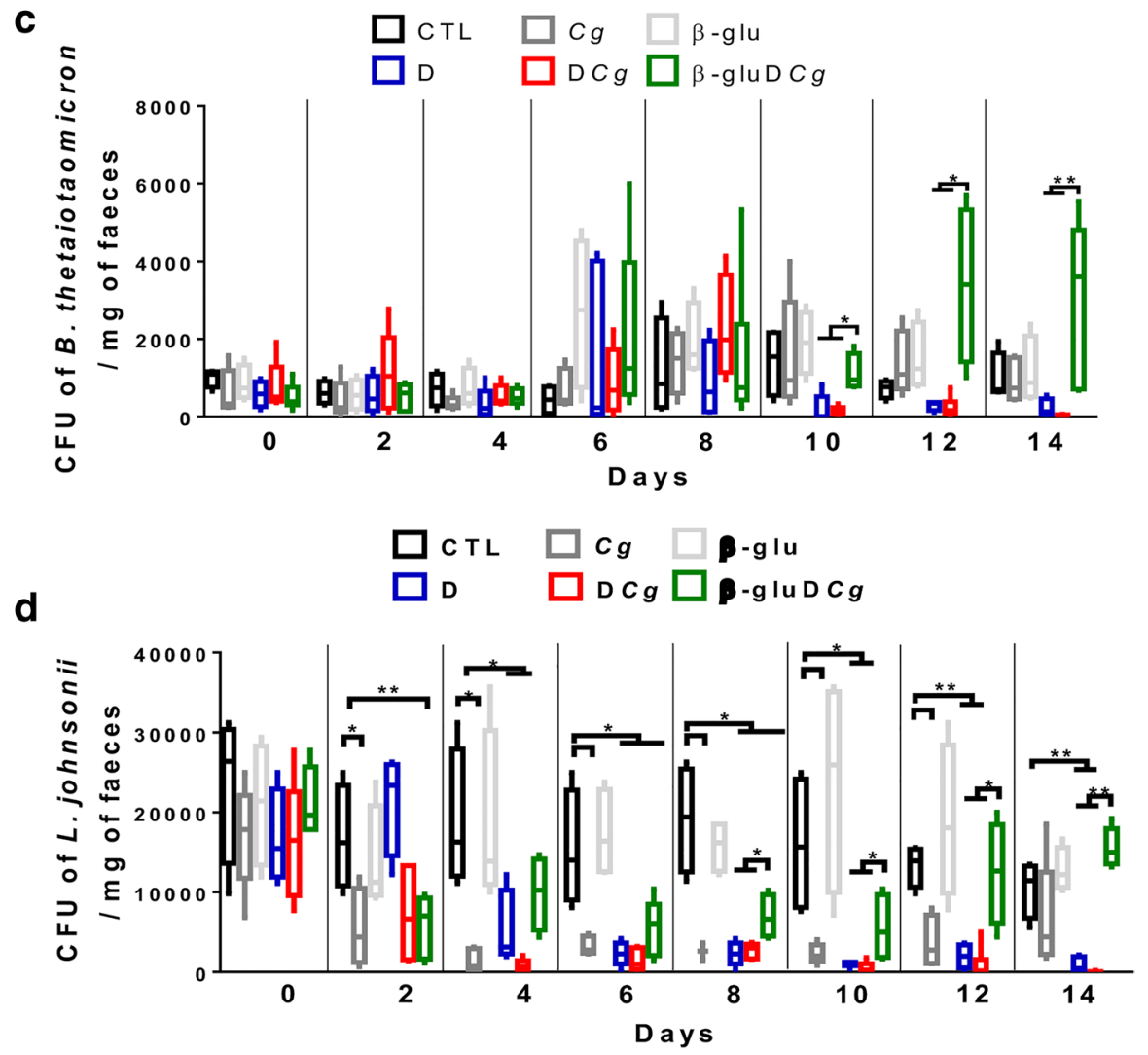

Fig. 3 Measurement of viable fecal bacteria in DSS-induced colitis. For all experiments, stool bacteria were isolated from mice on day 0 before $C$. glabrata challenge and DSS treatment. a-d Enumeration of E. coli, E. faecalis, B. thetaiotaomicron, and L. johnsonii CFUs in stool samples (**P $<0.001$, $\left.{ }^{*} \mathrm{P}<0.05\right)$ 

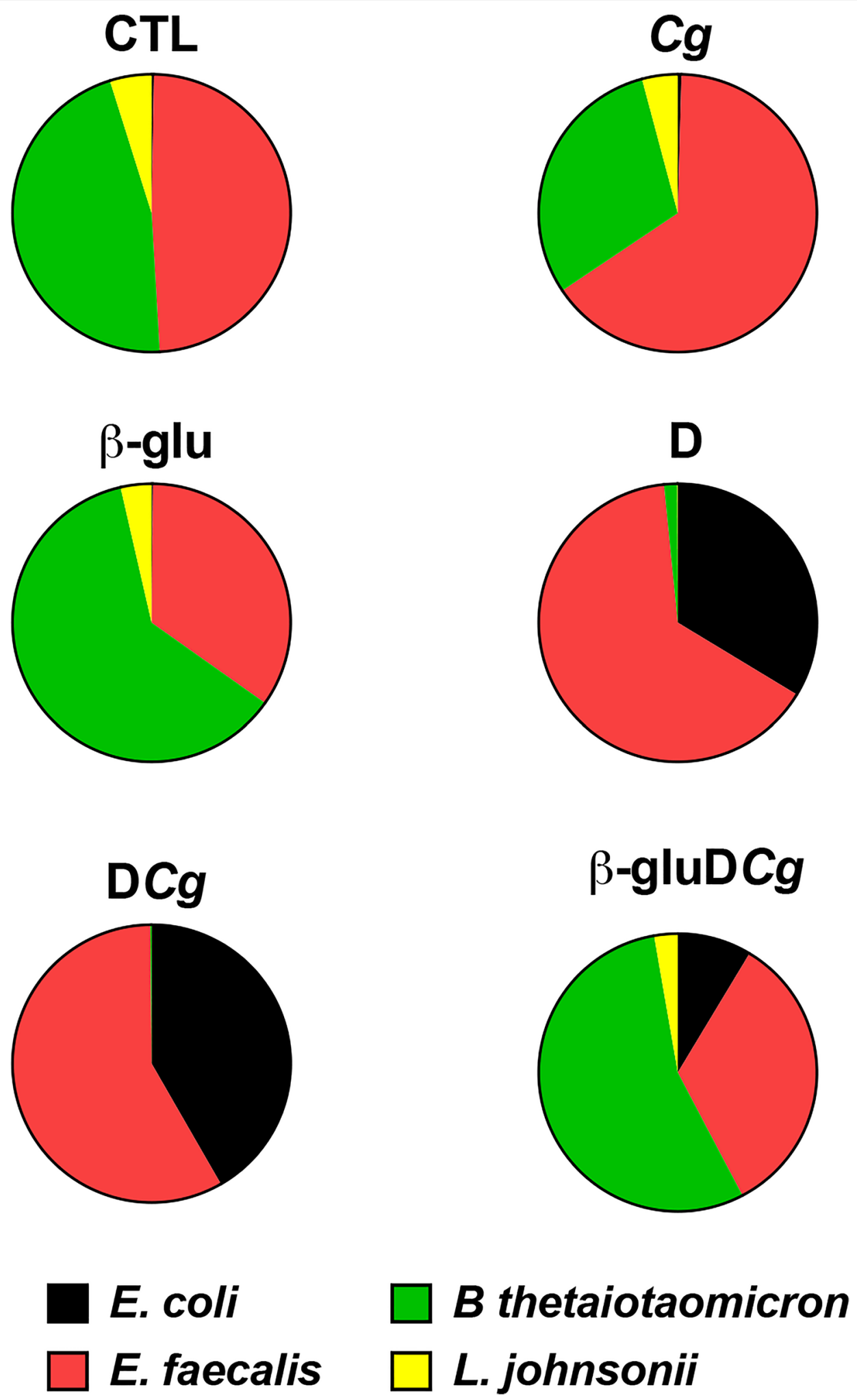

Fig. 4 Summary of the effects of $\beta$-glucan treatment on modulation of cultivable microbiota biodiversity in C. glabrata-DSS treated mice. Each color corresponds to the average percentage of each analyzed species of bacteria according to fourteen days of the experiment 


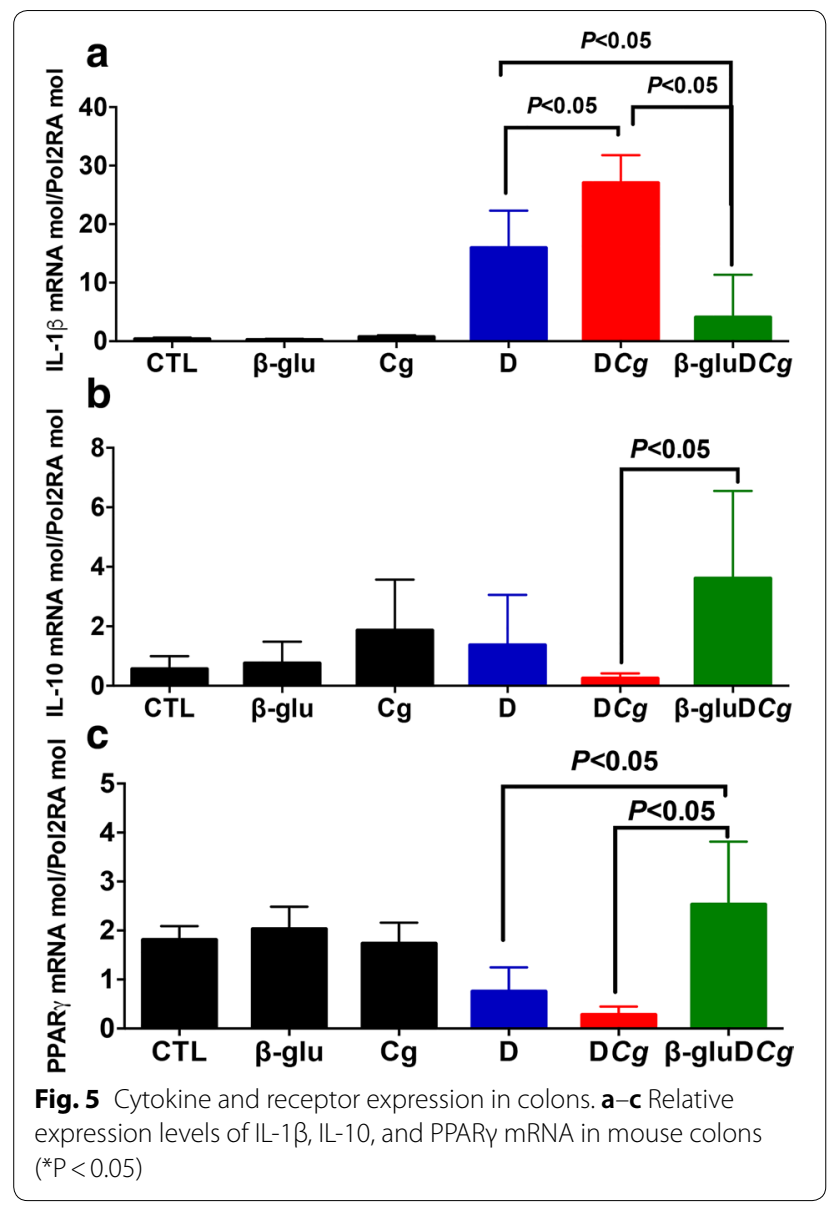

Biosystems). SYBR green dye intensity is assessed using one-step software [35]. The reference gene used to normalize the results is POLR2A47 [33].

\section{Statistical analysis}

All data are expressed as the mean \pm standard deviation for each experimental group. Pairs of groups are compared using the Mann-Whitney U test. Data are considered to be statistically significant when the $P$ value is as follows: $\mathrm{P}<0.05 ; \mathrm{P}<0.01 ; \mathrm{P}<0.001$. All statistical analyses are performed using GraphPad Prism 4.0 and XLSTAT.

\section{Authors' contributions}

$R C, C B, M B$, and $S$ J performed the experiments. $R C, C B, B S$ and $S J$ analyzed data. $R C, C B, M B, B S$ and $S J$ interpreted results of experiments. SJ designed the experiments and drafted the manuscript. All authors read and approved the final manuscript.

\section{Author details}

${ }^{1}$ U995/Team2, INSERM, 59000 Lille, France. ${ }^{2}$ LIRIC-INSERM U995/2, Lille Inflammation Research International Center, University Lille, 1 Place Verdun, 59000 Lille, France. ${ }^{3}$ Service de Parasitologie Mycologie, Pôle de Biologie Pathologie Génétique, CHU Lille, 59000 Lille, France.

\section{Acknowledgements}

The authors kindly thank Caroline François for her excellent technical assistance.

\section{Competing interests}

The authors declare that they have no competing interests.

\section{Availability of data and materials}

The datasets used and/or analyzed during the current study available from the corresponding author on reasonable request.

\section{Ethics approval and consent to participate}

Experiments were performed according to the protocols approved by the subcommittee for Research Animal Care of the Regional Hospital Centre of Lille, France, and in accordance with European legal and institutional guidelines (86/609/CEE) for the care and use of laboratory animals.

\section{Funding}

This work was supported by the ALLFUN (FP7 Health 260338 "ALLFUN" project "Fungi in the setting of inflammation, allergy and auto-immune diseases: translating basic science into clinical practices").

\section{Publisher's Note}

Springer Nature remains neutral with regard to jurisdictional claims in published maps and institutional affiliations.

Received: 18 September 2018 Accepted: 29 November 2018

Published online: 03 December 2018

\section{References}

1. Darfeuille-Michaud A, Neut C, Barnich N, Lederman E, Di Martino P, Desreumaux $P$, et al. Presence of adherent Escherichia coli strains in ileal mucosa of patients with Crohn's disease. Gastroenterology. 1998;115(6):1405-13.

2. Baumgart DC, Sandborn WJ. Inflammatory bowel disease: clinical aspects and established and evolving therapies. Lancet. 2007;369(9573):1641-57.

3. Jawhara S, Poulain D. Saccharomyces boulardii decreases inflammation and intestinal colonization by Candida albicans in a mouse model of chemically-induced colitis. Med Mycol. 2007;45(8):691-700.

4. Hoarau G, Mukherjee PK, Gower-Rousseau C, Hager C, Chandra J, Retuerto MA, et al. Bacteriome and mycobiome interactions underscore microbial dysbiosis in familial Crohn's disease. MBio. 2016;7(5):e01250.

5. Gouba N, Drancourt M. Digestive tract mycobiota: a source of infection. Med Mal Infect. 2015;45(1-2):9-16.

6. Lionakis MS, Netea MG. Candida and host determinants of susceptibility to invasive candidiasis. PLoS Pathog. 2013;9(1):e1003079.

7. Poulain D, Sendid B, Standaert-Vitse A, Fradin C, Jouault T, Jawhara S, et al. Yeasts: neglected pathogens. Dig Dis. 2009;27(Suppl 1):104-10.

8. Guerra Dore CM, Azevedo TC, de Souza MC, Rego LA, de Dantas JC, Silva FR, et al. Antiinflammatory, antioxidant and cytotoxic actions of betaglucan-rich extract from Geastrum saccatum mushroom. Int Immunopharmacol. 2007;7(9):1160-9.

9. Jawhara S, Habib K, Maggiotto F, Pignede G, Vandekerckove P, Maes

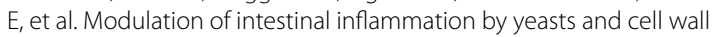
extracts: strain dependence and unexpected anti-inflammatory role of glucan fractions. PLoS ONE. 2012;7(7):e40648.

10. Zheng R, Jie S, Hanchuan D, Moucheng W. Characterization and immunomodulating activities of polysaccharide from Lentinus edodes. Int Immunopharmacol. 2005;5(5):811-20.

11. Soloviev DA, Jawhara S, Fonzi WA. Regulation of innate immune response to Candida albicans infections by alphaMbeta2-Pra1p interaction. Infect Immun. 2011;79(4):1546-58.

12. Brown GD, Gordon S. Immune recognition. A new receptor for betaglucans. Nature. 2001;413(6851):36-7.

13. Vancraeyneste H, Charlet R, Guerardel Y, Choteau L, Bauters A, Tardivel M, et al. Short fungal fractions of beta-1,3 glucans affect platelet activation. Am J Physiol Heart Circ Physiol. 2016;311(3):H725-34. 
14. Hugot JP, Chamaillard M, Zouali H, Lesage S, Cezard JP, Belaiche J, et al. Association of NOD2 leucine-rich repeat variants with susceptibility to Crohn's disease. Nature. 2001;411(6837):599-603.

15. Hart AL, Al-Hassi HO, Rigby RJ, Bell SJ, Emmanuel AV, Knight SC, et al. Characteristics of intestinal dendritic cells in inflammatory bowel diseases. Gastroenterology. 2005;129(1):50-65.

16. Darfeuille-Michaud A. Adherent-invasive Escherichia coli: a putative new E coli pathotype associated with Crohn's disease. Int J Med Microbiol. 2002:292(3-4):185-93.

17. Sepehri S, Kotlowski R, Bernstein CN, Krause DO. Microbial diversity of inflamed and noninflamed gut biopsy tissues in inflammatory bowel disease. Inflamm Bowel Dis. 2007;13(6):675-83.

18. Standaert-Vitse A, Sendid B, Joossens M, Francois N, Vandewalle-El Khoury P, Branche J, et al. Candida albicans colonization and ASCA in familial Crohn's disease. Am J Gastroenterol. 2009;104(7):1745-53.

19. Jawhara S, Thuru X, Standaert-Vitse A, Jouault T, Mordon S, Sendid B, et al. Colonization of mice by Candida albicans is promoted by chemically induced colitis and augments inflammatory responses through galectin-3. J Infect Dis. 2008;197(7):972-80.

20. Kim SC, Tonkonogy SL, Karrasch T, Jobin C, Sartor RB. Dual-association of gnotobiotic IL-10-/- mice with 2 nonpathogenic commensal bacteria induces aggressive pancolitis. Inflamm Bowel Dis. 2007:13(12):1457-66.

21. Darfeuille-Michaud A, Boudeau J, Bulois P, Neut C, Glasser AL, Barnich $\mathrm{N}$, et al. High prevalence of adherent-invasive Escherichia coli associated with ileal mucosa in Crohn's disease. Gastroenterology. 2004;127(2):412-21

22. Schumann S, Alpert C, Engst W, Loh G, Blaut M. Dextran sodium sulfateinduced inflammation alters the expression of proteins by intestinal Escherichia coli strains in a gnotobiotic mouse model. Appl Environ Microbiol. 2012;78(5):1513-22.

23. Bertin Y, Girardeau JP, Chaucheyras-Durand F, Lyan B, Pujos-Guillot E, Hare $J$, et al. Enterohaemorrhagic Escherichia coli gains a competitive advantage by using ethanolamine as a nitrogen source in the bovine intestinal content. Environ Microbiol. 2011;13(2):365-77.

24. Garsin DA. Ethanolamine utilization in bacterial pathogens: roles and regulation. Nat Rev Microbiol. 2010;8(4):290-5.

25. Erridge C, Duncan SH, Bereswill S, Heimesaat MM. The induction of colitis and ileitis in mice is associated with marked increases in intestinal concentrations of stimulants of TLRs 2, 4, and 5. PLoS ONE. 2010;5(2):e9125.
26. Lazaridou A Serafeimidou A Biliaderis CG, Moschakis T, Tzanetakis N. Structure development and acidification kinetics in fermented milk containing oat $\beta$-glucan, a yogurt culture and a probiotic strain. Food Hydrocol. 2014;39:204-14

27. Brown GD, Gordon S. Immune recognition of fungal beta-glucans. Cell Microbiol. 2005;7(4):471-9.

28. Masuda Y, Inoue H, Ohta H, Miyake A, Konishi M, Nanba H. Oral administration of soluble beta-glucans extracted from Grifola frondosa induces systemic antitumor immune response and decreases immunosuppression in tumor-bearing mice. Int J Cancer. 2013;133(1):108-19.

29. Stephen-Victor E, Karnam A, Fontaine T, Beauvais A, Das M, Hegde P, et al. Aspergillus fumigatus cell wall alpha-(1,3)-glucan stimulates regulatory T-cell polarization by inducing PD-L1 expression on human dendritic cells. J Infect Dis. 2017;216(10):1281-94.

30. Zhang J, Fu S, Sun S, Li Z, Guo B. Inflammasome activation has an important role in the development of spontaneous colitis. Mucosal Immunol. 2014;7(5):1139-50.

31. Cominelli F, Nast CC, Clark BD, Schindler R, Lierena R, Eysselein VE, et al. Interleukin 1 (IL-1) gene expression, synthesis, and effect of specific IL-1 receptor blockade in rabbit immune complex colitis. J Clin Invest. 1990;86(3):972-80.

32. Jawhara S, Mogensen E, Maggiotto F, Fradin C, Sarazin A, Dubuquoy L, et al. Murine model of dextran sulfate sodium-induced colitis reveals Candida glabrata virulence and contribution of beta-mannosyltransferases. J Biol Chem. 2012;287(14):11313-24.

33. Charlet $R$, Pruvost $Y$, Tumba G, Istel F, Poulain D, Kuchler $K$, et al. Remodeling of the Candida glabrata cell wall in the gastrointestinal tract affects the gut microbiota and the immune response. Sci Rep. 2018;8(1):3316.

34. Choteau L, Vancraeyneste $H$, Le Roy D, Dubuquoy L, Romani L, Jouault T, et al. Role of TLR1, TLR2 and TLR6 in the modulation of intestinal inflammation and Candida albicans elimination. Gut Pathog. 2017:9:9.

35. Choteau L, Parny M, Francois N, Bertin B, Fumery M, Dubuquoy L, et al. Role of mannose-binding lectin in intestinal homeostasis and fungal elimination. Mucosal Immunol. 2016;9(3):767-76.
Ready to submit your research? Choose BMC and benefit from:

- fast, convenient online submission

- thorough peer review by experienced researchers in your field

- rapid publication on acceptance

- support for research data, including large and complex data types

- gold Open Access which fosters wider collaboration and increased citations

- maximum visibility for your research: over $100 \mathrm{M}$ website views per year

At $\mathrm{BMC}$, research is always in progress.

Learn more biomedcentral.com/submissions 